\title{
Recovery, pathogenicity and molecular sequencing of Calonectria ilicicola which causes collar rot on Carica papaya in Australia
}

\author{
M. F. Male • Y. P. Tan • L. L. Vawdrey • R. G. Shivas
}

Received: 11 April 2012 / Accepted: 13 August 2012 /Published online: 18 September 2012

(C) Australasian Plant Pathology Society Inc. 2012

\begin{abstract}
Symptoms of collar rot were observed on 3month-old papaya plants cv. RB1. The pathogen was identified as Calonectria ilicicola based on disease symptoms, fungal morphology, pathogenicity and ITS sequencing.
\end{abstract}

Keywords Calonectria ilicicola $\cdot$ Collar rot · Papaya

Carica papaya L. is widely grown in tropical and subtropical regions of the world as a fruit tree crop. In Australia it is grown mostly for the fresh fruit market with $90 \%$ of production occurring in the wet tropics of northern Queensland.

In November 2010, in a 3-month-old field planting of papaya (cv RB1) at the Centre for Wet Tropics Agriculture in far north Queensland, a small number of plants were found with necrotic tissues at the basal stem and crown level. As the collar rot developed, these plants expressed symptoms of stunting, leaf chlorosis and lodging. Orange to red perithecia (Fig. 1) were visible at the base of the stem.

Sections of diseased plant material were surface-sterilised by immersion in $1.0 \%$ sodium hypochlorite solution (Northern Chemicals, Cairns, Australia) for 1 min., rinsed in sterile distilled water and dried between pieces of sterile

\footnotetext{
M. F. Male $\cdot$ L. L. Vawdrey $(\bowtie)$

Department of Agriculture, Fisheries and Forestry,

South Johnstone 4850 Qld, Australia

e-mail: lynton.vawdrey@daff.qld.gov.au

Y. P. Tan • R. G. Shivas

Plant Biosecurity Science, Department of Agriculture,

Fisheries and Forestry,

Dutton Park 4102 Qld, Australia

Present Address:

M. F. Male

Institute for Land Water and Society, Charles Sturt University,

Thurgoona 2640 NSW, Australia
}

paper. Small sections of diseased tissue were then taken from the margin of rot lesions and placed onto $2 \%$ potato dextrose agar amended with streptomycin sulfate $(40 \mathrm{U} / \mathrm{mL})$ $(\mathrm{PDA}+\mathrm{S})$ and incubated at $27{ }^{\circ} \mathrm{C}$ in the dark for $72 \mathrm{~h}$. Colonies recovered were subcultured onto $\mathrm{PDA}+\mathrm{S}$ and incubated for a further $96 \mathrm{~h}$ in the dark at $27{ }^{\circ} \mathrm{C}$ before exposure to near-UV light with a $12 \mathrm{~h}$ photoperiod to induce sporulation.

Colonies were fast growing with abundant white, floccose, aerial mycelia and in reverse salmon coloured. Orange to red perithecia appeared after 20 days. Asci were clavate $90-140 \times 12-20 \mu \mathrm{m}$, contained eight ascospores, and tapered to a long thin stalk. Ascospores were hyaline, fusoid, slightly curved, 35-50×6-8 $\mu \mathrm{m}$. Macroconidia (Fig. 2) were hyaline, cylindrical, 1-3 septate, 45-90 $\times 4-7 \mu \mathrm{m}$, borne on branched, nonseptate conidiophores. Colonies were tentatively identified on the basis of anamorph and teleomorph morphology as Calonectria ilicicola Boedijn \& Reitsma 1950. A single isolate was lodged in the Plant Pathology Herbarium (BRIP) in Brisbane as BRIP 53933.

Mycelium from isolate BRIP 53933 was placed in a $2.0 \mathrm{~mL}$ safe-lock tube. The equivalent of $0.5 \mathrm{~mL}$ of $0.5 \mathrm{~mm}$ glass beads (Daintree Scientific, St Helens, Australia) was added and the mycelium was lysed using the Tissue Lyser (Qiagen, Melbourne, Victoria, Australia) for $1 \mathrm{~min}$ at $30 \mathrm{hz} / \mathrm{s}$. DNA was extracted from this mixture using the Gentra Puregene kit (Qiagen), following the manufacturer's instructions. PCR amplification was conducted using the Phusion High-Fidelity PCR Master Mix (Finnzymes, Espoo, Finland), which consisted of $12.5 \mu \mathrm{L}$ of $2 \times$ Master Mix with HF Buffer, $0.5 \mu \mathrm{L}$ each of $10 \mathrm{mM}$ forward and reverse primers, and $1 \mu \mathrm{L}$ of DNA template. The internal transcribed spacer (ITS) region of the nrDNA was amplified with primers ITS1 and ITS4 (Carbone and Kohn 1999), and part of the histone 3 (H3) gene was amplified with primers CYLH3F and CYLH3R (Crous et al. 2004). PCR products 


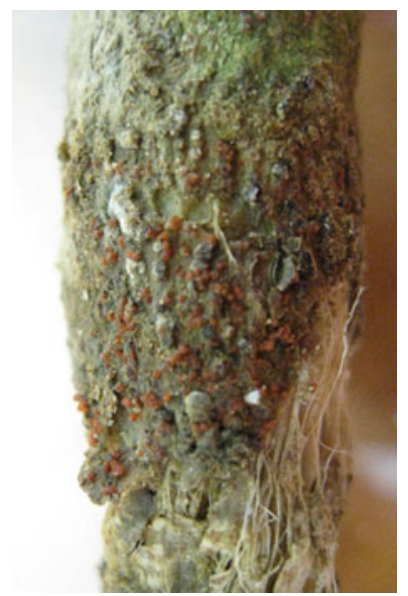

Fig. 1 Calonectria ilicicola. Orange to red perithecia at the base of the stem

were amplified in a Bio-Rad C1000 thermal cycler (BioRad, Hercules, USA) using the following conditions: $98^{\circ} \mathrm{C}$ for $30 \mathrm{~s}, 30$ cycles at $98^{\circ} \mathrm{C}$ for $10 \mathrm{~s}, 55^{\circ} \mathrm{C}$ for $30 \mathrm{~s}, 72^{\circ} \mathrm{C}$ for $30 \mathrm{~s}$, followed by a $5 \mathrm{~min}$ final extension at $72{ }^{\circ} \mathrm{C}$. The products were sequenced by Macrogen Incorporated (Seoul, Korea) using the AB 3730xl DNA Analyser (Applied Biosystems, Forster City, California, USA). The sequences obtained were compared to the nucleotide sequence database, GenBank, using the nucleotide query BLASTn accessed via the National Centre for Biotechnology Information website (http://www.ncbi.nlm.nih.gov/). The ITS and H3 sequences of BRIP 53933 (GenBank accession JQ809270 and JQ809271, respectively) were $99 \%$ similar to the ex-type culture of $C$. ilicicola strain CBS 190.50 (GQ280605, AY725676).

Axenic broth cultures were produced by transferring mycelial plugs taken from the margin of a 3-day-old culture (BRIP 53933) grown on $1 / 2 \mathrm{PDA}+\mathrm{S}$ into $50 \mathrm{~mL}$ of $2 \%$ malt

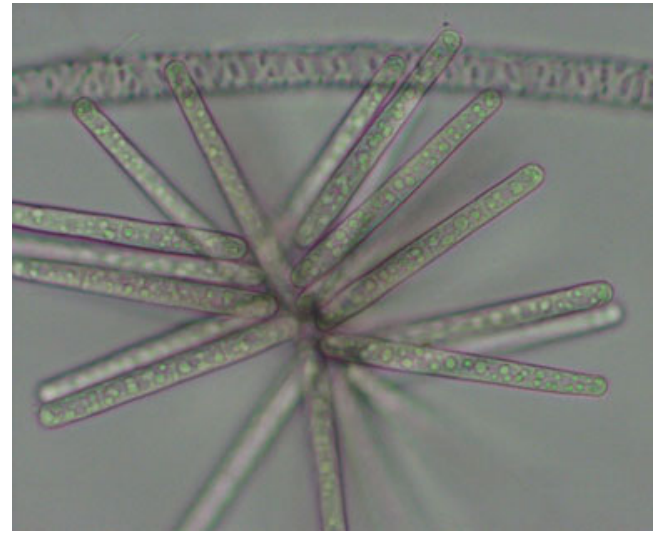

Fig. 2 Calonectria ilicicola. Hyaline, cylindrical, macroconidia extract broth in $250 \mathrm{~mL}$ Erlenmeyer flasks. After 8 weeks, mycelial mats were rinsed with distilled water before being macerated in distilled water in a Waring blender to produce a hyphal suspension. A single 9-week-old papaya seedling (cv RB1) was transplanted into each of eight $15-\mathrm{cm}-$ diameter pots containing autoclaved field soil. Seven days after transplanting, $40 \mathrm{~mL}$ of the hyphal suspension was injected with a $60 \mathrm{~mL}$ eccentric tip syringe (Terumo Medical Corporation, Elkton, USA) into the soil at four equidistant sites around the base of the transplanted seedlings. Six pots were inoculated with the hyphal suspension and two untreated pots served as controls. Control pots were injected with sterile water only. All seedlings were placed in plastic trays containing water to a depth of $5 \mathrm{~cm}$ to replicate water logged soil that is known to favour collar rot development. After 3 days, pots were removed from the trays and the soil kept moist using overhead watering. A decay at the base of the stem appeared in inoculated plants after 20 days. No disease symptoms occurred in the control pots. Calonectria ilicicola was recovered and identified by the morphological characters mentioned previously thereby fulfilling Koch's postulates.

Calonectria ilicicola is known to infect a number of important tropical and subtropical crops around the world (Crous 2002). Recently it was recorded in Italy on potted Laurus nobilis plants in a nursey (Polizzi et al. 2012) and in Australia on avocado (Dann et al. 2012). It has also been reported on papaya in Hawaii (Laemmlen and Aragaki 1971) and Brazil (Crous 2002). To our knowledge this is the first time molecular data of this fungal pathogen in Australia have been provided.

\section{References}

Carbone I, Kohn LM (1999) A method for designing primer sets for speciation studies in filamentous ascomycetes. Mycologia 91:553-556

Crous PW (2002) Taxonomy and pathology of Cylindrocladium (Calonectria) and Allied Genera. APS Press, St. Paul

Crous PW, Groenewald JZ, Rised J-M, Simoneau P, Hywel-Jones NL (2004) Calonectria species and their Cylindrocladium anamorphs: species with sphaeropedunculate vesicles. Stud Mycol 50:415-430

Dann EK, Cooke AW, Forsberg LI, Pegg KG, Tan YP, Shivas RG (2012) Pathogenicity studies in avocado with three nectriaceous fungi, Calonectria ilicicola, Gliocladiopsis sp. and Ilyonectria liriodendri Plant Pathology [Online] doi:10.1111/j.13653059.2011.02579.x

Laemmlen FF, Aragaki M (1971) Collar rot of papaya caused by Calonectria sp. Plant Dis Rep 55:743-745

Polizzi G, Vitale A, Aiello D, Guarnaccia V, Crous P, Lombard L (2012) First report of Calonectria ilicicola causing a new disease on laurus (Laurus nobilis). J Phytopathol 160(1):41-44 